CYSTIC FIBROSIS

\title{
Nitric oxide synthase 1 as a potential modifier gene of decline in lung function in patients with cystic fibrosis
}

\author{
J Texereau, S Marullo, D Hubert, J Coste, D J Dusser, J Dall'Ava-Santucci, A T Dinh-Xuan
}

Thorax 2004;59:156-158. doi: 10.1136/thorax.2003.006718

See end of article for authors' affiliations

.....................

Correspondence to: Professor A T Dinh-Xuan Service de PhysiologieExplorations

Fonctionnelles, Hôpital Cochin, 27 rue du faubourg Saint-Jacques, 75014 Paris, France; anh-tuan.dinh-xuan@ cch.ap-hop-paris.fr

Received 13 March 2003 Accepted 15 October 2003

\begin{abstract}
Background: The severity of lung disease varies widely in patients with cystic fibrosis (CF) who have the same type of mutations of the cystic fibrosis transmembrane regulator (CFTR) gene, suggesting involvement of "modifier" genes. The nitric oxide synthase 1 (NOS1) gene is a candidate for this role because exhaled nitric oxide (NO) is reduced in patients with CF and NOS1 activity contributes to transepithelial ionic transport, immune defence, and non-specific inflammation of the airways.

Methods: Dinucleotide GT repeat polymorphism was studied in the $5^{\prime}$ untranslated region of the NOS 1 gene, immediately upstream from the transcription initiation site, in 59 patients with CF and 59 healthy controls.

Results: Nineteen alleles of the NOS1 gene were identified according to the number of GT repeats (from 18 to 36) in the 5 untranslated region. Exhaled NO levels were significantly correlated with the number of GT repeats. Patients with CF who had the NOS1 genotype associated with high NO production had a slower decline in lung function during the 5 year follow up period. There was no confounding effect of age, chronic bacterial colonisation of the airway, or CFTR genotype.

Conclusions: These data suggest a possible link between the NOS1 gene locus and the rate of decline in lung function in patients with CF.
\end{abstract}

C ystic fibrosis (CF), a genetic disorder caused by mutations of the cystic fibrosis transmembrane conductance regulator (CFTR) gene, is characterised by severe lung disease. While CFTR mutations are closely correlated with the pancreatic status, the prognosis of lung, liver and gastrointestinal disease is only marginally predicted from the CFTR genotype and might reflect the additional influence of environmental factors and the concurrent expressions of "modifier" genes. Likely candidates are genes encoding proteins or enzymes involved in inflammation, immunity, infection, and ion transport. ${ }^{1}$

Nitric oxide (NO) is synthesised from L-arginine by nitric oxide synthases (NOS). All three isoforms (NOS1, NOS2, NOS3) are expressed in the respiratory tract and polymorphisms of NOS genes have been described in lung disease. In particular, NOSI expression is decreased in epithelial cells from the upper airways of patients with $\mathrm{CF}^{2}$ It was proposed that reduced expression of NOS I could be the cause of the unexpected low or normal exhaled NO concentrations, notwithstanding the presence of chronic inflammation and bacterial colonisation in the airways of CF patients. ${ }^{3}$

The proximal region of the NOSI gene contains dinucleotide GT repeats that are located immediately upstream of the transcription start site, next to transcription factor binding sites. Although variants of this region, which exhibits a high heterozygosity index, are not yet fully characterised in humans, gene reporter assays suggest that changes in the structure of NOS1 5' -untranslated region (UTR) can markedly affect gene expression and transcription efficiency. ${ }^{4}$ In this study we analysed sequence variations of NOS1 5'-UTR and sought to determine whether the number of GT repeats affects NOSI activity, lung NO production, and decline of lung function in patients with CF.

\section{METHODS}

\section{Patients}

White adult patients with CF and healthy volunteers without recent respiratory tract infections, corticosteroid medication, or tobacco use participated in the study. The diagnosis of CF was based on medical records, repeated sweat chloride tests, and the identification of CFTR gene mutations. Patients with one or two CFTR mutations of classes 4 or 5 were classified in the "mild" CFTR genotype group whereas patients with two mutations of classes 1, 2 or 3 were considered as having "severe" CFTR genotype. ${ }^{1}$

Annual spirometric data (collected from the 5 years before study entry) were used to calculate annual rate of decline (based on a mean of five measurements) of forced expiratory volume in 1 second $\left(\mathrm{FEV}_{1}\right)$ in each patient (simple linear regression, accepted $R^{2}$ value $>0.30$ ).

The study was approved by the local ethical committee and written informed consent was obtained from all subjects.

\section{Exhaled NO measurements}

Exhaled NO was measured using a chemiluminescence analyser ( $\mathrm{NOA}^{\mathrm{TM}} 280$, Sievers, Boulder, CO, USA), sampled in triplicate at a controlled outflow of $100 \mathrm{ml} / \mathrm{s}$, and the mean values recorded according to international guidelines. ${ }^{5}$

\section{NOS 1 genotype determination}

Genomic DNA extracted from blood mononuclear cells was used for polymerase chain reaction (PCR) amplification $\left(95^{\circ} \mathrm{C}\right.$ for 1 minute, 40 cycles of $95^{\circ} \mathrm{C}, 10 \mathrm{~s} ; 67^{\circ} \mathrm{C}, 30 \mathrm{~s}$; $68^{\circ} \mathrm{C}, 12 \mathrm{~s}$; final extension at $68^{\circ} \mathrm{C}$ for 2 minutes) with 5-CCTGCGTGGCTACTACATTC-3 (forward) and 5TGGGTGTGGGGAGGGAGAC-3 (reverse) primers. After purification (Qiaquick PCR purification kit, Qiagen Inc), PCR products were sequenced to determine the number of GT repeats in the polymorphic region. PCR products from homozygous subjects were separated by electrophoresis in $3 \%$ agarose gels and used as standards to determine the number of repeats in the PCR products obtained from subsequent individuals. 


\section{Statistical analysis}

Data were expressed as mean (SD) or percentage with 95\% confidence intervals (CI). To assess the combined effect of both alleles on outcome we categorised the alleles above and below the median of GT repeats (27) and the genotypes into three classes $(0,1$ or 2 alleles containing more than 27 GT repeats). Mean NO levels and $\mathrm{FEV}_{1}$ were compared between groups by one way or two way analyses of variance. The Kolmogorov-Smirnov goodness of fit test was used to ascertain that the data were normally distributed before the analysis. Distributions were compared using $\chi^{2}$ analysis; $p$ values of $<0.05$ were considered statistically significant.

\section{RESULTS}

Fifty nine volunteers (39 men) of mean (SD) age 37.4 (2.3) years and 59 adult patients with CF were studied (table 1). Nineteen NOSI alleles were identified, the number of GT repeats in the 5'-UTR region ranging from 18 to 36 . NOS1 genotype distribution was similar in both groups with $24 \%, 54 \%$ and $22 \%$ of controls and $27 \%, 41 \%$ and $32 \%$ of patients displaying 0,1 , and 2 alleles, respectively, with more than 27 repeats $\left(\chi^{2}=2.401\right.$, NS).

Exhaled NO values were (plausibly) normally distributed $(\mathrm{Z}=1.284$, NS). Global comparison by one way ANOVA showed a significant association between NOSI genotype classes and exhaled NO ( $\mathrm{F}=5.078, \mathrm{p}=0.008$; fig 1$)$. Two way ANOVA showed that the effect of the number of GT repeats on exhaled NO was independent of the group (controls or patients, $\mathrm{p}=0.003$ ). Interaction between group and genotype did not reach statistical significance $(p=0.08)$.

Annual decline in $\mathrm{FEV}_{1}$ was (plausibly) normally distributed among patients $(\mathrm{Z}=1.211$, NS). The retrospective analysis of lung function during the 5 years preceding the study showed different trends according to NOS1 genotype class $(p=0.025)$ which could not be explained by other clinical parameters (table 1). The annual percentage loss of $\mathrm{FEV}_{1}$ was $3.3 \%$ (95\% CI 1.1 to 5.4 ), 3.2\% (95\% CI 2.4 to 4.0 ), and $0.8 \%(-0.5$ to 2.1$)$ for patients with 0,1 , and 2 alleles with $>27$ repeats, respectively.

\section{DISCUSSION}

Over a 5 year period patients with CF displaying more than 27 GT repeats in the $5^{\prime}$-UTR of each NOS1 allele had a lower annual $\mathrm{FEV}_{1}$ loss than patients with 27 repeats or less in at least one allele.

Previous studies have indicated that the NOS1 locus affects lung disease in patients with $\mathrm{CF}^{6}{ }^{6}$ although the pathophysiological basis for this association remains elusive.

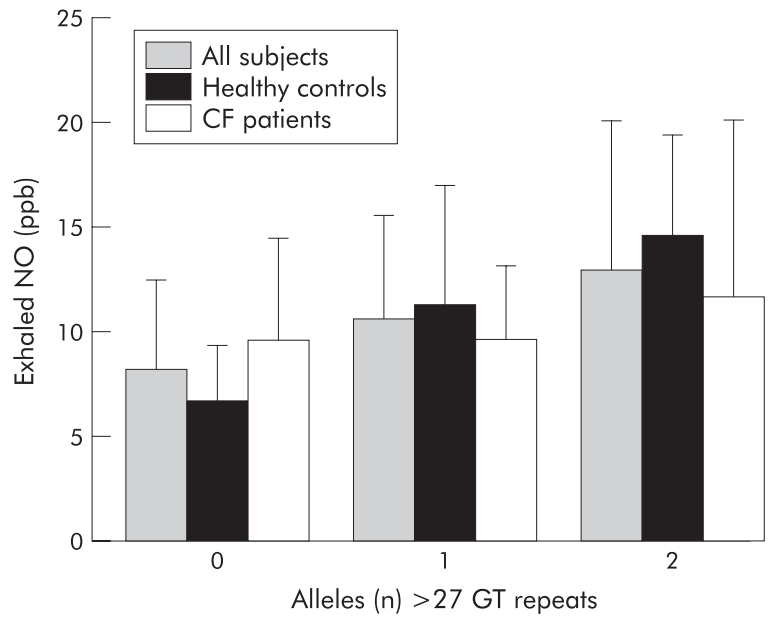

Figure 1 Exhaled NO (in ppb) in controls and patients grouped as a function of the number of alleles containing more than 27 repeats. Values are from left to right: all subjects: 8.1 (95\% Cl 6.5 to $9.6, n=30)$, $10.5(95 \% \mathrm{Cl} 9.1$ to $11.8, \mathrm{n}=56)$, and $12.7(95 \% \mathrm{Cl} 10.1$ to 15.2 , $n=32)(p=0.008$, ANOVA; healthy controls: $6.4(95 \% \mathrm{Cl} 4.9$ to 7.9 , $\mathrm{n}=14), 11.1(95 \% \mathrm{Cl} 9.1$ to $13.2, \mathrm{n}=32)$, and $14.5(95 \% \mathrm{Cl} 11.8$ to 17.1, $\mathrm{n}=13)$; $\mathrm{CF}$ patients: $9.5(95 \% \mathrm{Cl} 7.1$ to $11.9, \mathrm{n}=16) ; 9.5(95 \% \mathrm{Cl}$ 8.0 to $11.0, n=24)$, and $11.4(95 \% \mathrm{Cl} 7.5$ to $15.3, \mathrm{n}=19)$.

Expression of NOS1 is dynamically regulated by changes in gene transcription occurring via alternative splicing within the $5^{\prime}$-UTR. ${ }^{4}$ Because the GT polymorphism investigated here occurs immediately upstream of the transcription start site of NOS1, it might affect the binding affinity of transcription factors ${ }^{7}$ which target DNA binding sites located in the vicinity of the repetitive sequence. The number of GT repeats of NOSI correlated with exhaled NO concentrations, as reported in previous studies of NOSI polymorphism affecting intronic regions. ${ }^{6}{ }^{8}$ Correlation, however, might be partially blunted by factors affecting exhaled NO measurements in CF-for example, altered NO diffusion across the thickened airway mucosal barrier, increased NO consumption by denitrifying bacteria, and combination of $\mathrm{NO}$ with reactive oxygen species. ${ }^{9}$

Although CF is a monogenic disease, previous studies have suggested that additional genes could modulate its clinical outcome. ${ }^{1}$ Variations in exhaled NO concentrations, associated with an intronic repeat polymorphism of NOSI, were found to modulate chronic colonisation of the airway with Pseudomonas aeruginosa and Aspergillus fumigatus. ${ }^{6}$ This

\begin{tabular}{|c|c|c|c|}
\hline & \multicolumn{3}{|c|}{ Number of alleles with more than 27 repeats } \\
\hline & 0 & 1 & 2 \\
\hline Patients (n) & 16 & 24 & 19 \\
\hline Age (years) & $31.4(8.3)$ & $28.9(8.3)$ & $28.8(7.5)$ \\
\hline$M: F$ & $11: 5$ & $11: 13$ & $12: 7$ \\
\hline CFTR genotype (S/M/ND) & $13 / 1 / 2$ & $18 / 1 / 5$ & $12 / 1 / 6$ \\
\hline Diabetes (n) & 4 & 3 & 1 \\
\hline Pancreatic insufficiency (n) & 15 & 20 & 17 \\
\hline $\mathrm{BMI}\left(\mathrm{kg} / \mathrm{m}^{2}\right)$ & $19.0(2.2)$ & $18.9(2.3)$ & $18.8(1.7)$ \\
\hline \multirow{2}{*}{\multicolumn{4}{|c|}{ Annual FEV loss (\% predicted) }} \\
\hline & & & \\
\hline Mean & 3.3 & 3.2 & 0.8 \\
\hline $95 \% \mathrm{Cl}$ & 1.1 to 5.4 & 2.4 to 4.0 & -0.5 to 2.1 \\
\hline
\end{tabular}

$\mathrm{CFTR}=$ cystic fibrosis transmembrane regulator; $\mathrm{BMI}=$ body mass index; $\mathrm{n}=$ number of patients in each category; $\mathrm{S}$, $M$ and $N D=$ severe, mild and not determined CFTR genotypes, respectively.

When appropriate, values are expressed as mean (SD). No statistical differences were found (using $\chi^{2}$ analysis for categories and ANOVA for continuous variables) except for decline in lung function $(p=0.025)$.

${ }^{*}$ Colonisation with $P$ aeruginosa/B cepacia. 
association was not found in our study, probably because of the high prevalence of chronic bronchial colonisation in this cohort of adult patients. In addition, except for a decline in lung function, no clinical differences were seen between the three NOS1 genotype groups (table 1). Other parameters which are not readily accessible to clinical investigation such as transepithelial ion transport, bronchomotor tone, or pulmonary inflammation ${ }^{10}$ can vary as a function of NO production, thus affecting the mechanisms controlling lung function decline in CF patients.

Although our results are preliminary and limited by the size of the investigated population, they show an association between the NOSI gene locus and progression of lung disease in patients with CF which is independent of the CFTR genotype. These findings suggest that NOSI variants leading to reduced NO production might be important for understanding the phenotypic disparities of patients with the same CFTR mutations. Further investigations are needed to establish the biological consequences of this repeat polymorphism on NOS1 function.

\section{Authors' affiliations}

J Texereau, J Dall'Ava-Santucci, A T Dinh-Xuan, Service de PhysiologieExplorations Fonctionnelles, Hôpital Cochin, AP-HP, Université Paris 5, Paris, France

S Marullo, Department of Cell Biology, Institut Cochin, INSERM, CNRS, Paris, France

D Hubert, D J Dusser, Service de Pneumologie, Hôpital Cochin, AP-HP, Université Paris 5, Paris, France
J Coste, Service d'Informatique Médicale et de Biostatistiques, Hôpital Cochin, AP-HP, Université Paris 5, Paris, France

This work was supported by grants from the Legs Poix, Chancellerie des Universités, Académie de Paris, France.

\section{REFERENCES}

1 Zielenski J. Genotype and phenotype in cystic fibrosis. Respiration 2000:67:117-33.

2 Dotsch J, Puls J, Klimek T, Rascher W. Reduction of neuronal and inducible nitric oxide synthase gene expression in patients with cystic fibrosis. Eur Arch Otorhinolaryngol 2002;259:222-6.

3 Thomas SR, Kharitonov SA, Scott SF, et al. Nasal and exhaled nitric oxide is reduced in adult patients with cystic fibrosis and does not correlate with cystic fibrosis genotype. Chest 2000;117:1085-9.

4 Wang Y, Newton DC, Robb GB, et al. RNA diversity has profound effects on the translation of neuronal nitric oxide synthase. Proc Natl Acad Sci USA 1999:96:12150-5.

5 Kharitonov SA, Alving K, Barnes PJ. Exhaled and nasal nitric oxide measurements: recommendations. The European Respiratory Society Task Force. Eur Respir J 1997; 10:1683-93.

6 Grasemann H, Knauer N, Buscher R, et al. Airway nitric oxide levels in cystic fibrosis patients are related to a polymorphism in the neuronal nitric oxide synthase gene. Am J Respir Crit Care Med 2000;162:2172-6.

7 Park CS, Krishna G, Ahn MS, et al. Differential and constitutive expression of neuronal, inducible, and endothelial nitric oxide synthase mRNAs and proteins in pathologically normal human tissues. Nitric Oxide 2000:4:459-71.

8 Wechsler ME, Grasemann H, Deykin A, et al. Exhaled nitric oxide in patients with asthma: association with NOS1 genotype. Am J Respir Crit Care Med 2000;162:2043-7.

9 van der Vliet A, Cross CE. Phagocyte oxidants and nitric oxide in cystic fibrosis: new therapeutic targets? Curr Opin Pulm Med 2000;6:533-9.

10 Ricciardolo FL. Multiple roles of nitric oxide in the airways. Thorax 2003;58: 175-82. 